\title{
Demographic Characteristics and Etiology of Hydrocephalus Patients attended at Tertiary Care Hospital in Bangladesh
}

\author{
Md. Mahfuzur Rahman ${ }^{1}$, Mohammad Ashraful Haque², Mohammad Rafiqul Islam³, \\ Md. Abdus Salam, Kalim Uddin', Md. Mizanur Rahman ${ }^{6}$, Md. Moajjam Hossain Talukder, \\ Md. Aminul Hasanat ${ }^{8}$, Md. Afzal Hossain ${ }^{9}$ \\ ${ }^{1}$ Assistant Professor, Department of Neurotrauma Surgery, National Institute of Neurosciences \& Hospital, Dhaka, Bangladesh; \\ ${ }^{2}$ Assistant Professor, Department of Neurosurgery, National Institute of Neurosciences \& Hospital, Dhaka, Bangladesh; \\ ${ }^{3}$ Assistant Professor, Department of Neurosurgery, Dhaka Medical College, Dhaka, Bangladesh; ${ }^{4}$ Associate Professor, \\ Department of Neurotrauma Surgery, National Institute of Neurosciences \& Hospital, Dhaka, Bangladesh; \\ ${ }^{5}$ Registrar, Department of Neurotrauma Surgery, National Institute of Neurosciences \& Hospital, Dhaka, \\ Bangladesh; ${ }^{\top}$ Junior Consultant (Orthopedics), Gafargaon Upazila Health Complex, Mymensingh, \\ Bangladesh; ${ }^{7}$ Assistant Professor, Department of Neurosurgery, National Institute of \\ Neurosciences \& Hospital, Dhaka, Bangladesh; ${ }^{8}$ Junior Consultant, Department of \\ Anesthesiology, National Institute of Neurosciences \& Hospital, Dhaka, \\ Bangladesh; ${ }^{9}$ Professor \& Chairman, Department of Neurosurgery, \\ Bangabandhu Sheikh Mujib Medical University, Dhaka, Bangladesh
}

[Received: January 2015; Revised: March 2015; Accepted: June 2015; Published: July 2015]

\begin{abstract}
Background: Hydrocephalous can occur at any age. Objectives: The purpose of the present study was to see the Demographic Characteristics and Etiology of Hydrocephalus Patients. Methodology: This cross sectional study was conducted in the Department of Neurosurgery at Bangabandhu Sheikh Mujib Medical University, Dhaka from April 2009 to September 2010 for a period of one and half year. Patients presented with obstructive hydrocephalus at any age with both sexes were included as study population. Detailed socio-demographic history as well as the associated etiological factors was recorded in pre designed data collection sheet. Result: A total number of 60 obstructive hydrocephalous patients were recruited for this study after fulfilling the inclusion and exclusion criteria. The mean age with SD was 17.95 \pm 19.15 . Acquedctal stenosis was the most common etiology of hydrocephalous which was $31(51.7 \%)$ cases followed by posterior fossa midline tumour, CPA tumour and pineal region tumour which were 14 (23.3\%) cases, $9(15.0 \%)$ cases and 6(10.0\%) cases respectively. Conclusion: Obstructive hydrocephalous is most commonly found in younger age group which is caused by acquedctal stenosis. [Journal of National Institute of Neurosciences Bangladesh, 2015;1(2): 47-49]
\end{abstract}

Keywords: Demographic Characteristics; Etiology; Hydrocephalus

Correspondence: Dr. Md. Mahfuzur Rahman, Assistant Professor, Department of Neurotrauma Surgery, National Institute of Neurosciences \& Hospital, Dhaka, Bangladesh; Email: dr.mahfuz.ns76@gmail.com; Cell no.: +8801711076764

Conflict of interest: There is no conflict of interest to any of the authors of this article.

Funding agency: The study was not funded by any authority.

Contribution to authors: MMR \& MAH were contributed from protocol preparation up to report writing. KU, MAS, MMR, MRI, MAH \& MAH have prepared the manuscript and have revised the manuscript.

How to cite this article: Rahman MM, Haque MA, Islam MR, Salam MA, Uddin K, Rahman MM, Talukder MMH, Hasanat MA, Hossain MA. Demographic Characteristics and Etiology of Hydrocephalus Patients attended at Tertiary Care Hospital in Bangladesh. J Natl Inst Neurosci Bangladesh, 2015;1(2): 47-49

\section{Introduction}

Hydrocephalus is an abnormal enlargement of the ventricles due to an excessive accumulation of CSF resulting from a disturbance of its flow, absorption or, uncommonly, secretion ${ }^{1}$. The incidence of hydrocephalus in the new born varies from 0.2-0.5 per 1000 birth $^{2}$.

Little is known about the factors influencing the development of hydrocephalus. Stoll et $\mathrm{al}^{3}$ studied environmental and genetic factors in congenital 
hydrocephalus $(\mathrm{CH})$ in 96 children. It has been reported 33 teratogenic agents including physical injury, irradiation, nutritional deficiency, nutrition excess and various chemicals and drugs which produce hydrocephalus ${ }^{4}$. It was found that there was a positive correlation between the higher dose of radiation and production of hydrocephalus in children conceived during the period of radiation fall out ${ }^{5}$. Experimental observations have shown that intrauterine viral infection may also cause hydrocephalus ${ }^{2}$. Obstructive hydrocephalus is one of the common conditions in neurology hospital which requires surgery. Therefore it is important to know the etiological factors as well as the demographics characteristics of obstructive hydrocephalous patients.

\section{Methodology}

This was a cross sectional study which was conducted the Department of Neurosurgery at Bangabandhu Sheikh Mujib Medical University, Dhaka, Bangladesh from April 2009 to September 2010 for a period of one and half year. All patients presenting with obstructive hydrocephalus and age more than 6 months were included as study population. Communicating hydrocephalus, previously shunted patient, abnormal ventricular anatomy in imaging were excluded from this study. Detailed information regarding severe systemic diseases like DM, HTN, age less $<6$ months, post menifgngitic hydrocephalus were recorded. On admission, a detailed history was taken from the patient or from patient's attendants. Thorough general and neurological examinations were carried out by the researcher himself. Images findings (CT scan and MRI) were used to confirm hydrocephalus. Prior to commencement of this study, the research protocol was approved by the ethical review committee of BSMMU. All the data were checked and edited after collection. Then the collected data were analyzed by SPSS $16^{\text {th }}$ version (statistical package for social science) computer software program. Percentage was calculated to determine the proportion of the findings. Results were presented in tabulated form. Statistical significance was set at $\mathrm{p}<0.05$

\section{Results}

A total number of 60 patients were recruited for this study after fulfilling the inclusion and exclusion criteria.

Majority were in the age group of 0.6 to 10 years of age group which was $32(53.3 \%$ ) cases followed by 11 to 20 years, 41 to 50 years and 31 to 40 years which were $9(15.0 \%)$ cases, $6(10.0 \%)$ and $5(8.3 \%)$ cases respectively. Minimum age of hydrocephalous was 6 months. Maximum age of hydrocephalous was 70 years. The mean age with SD was $17.95 \pm 19.15$ (Table 1).

Table 1: Distribution of the Patients according to Age

\begin{tabular}{lcc}
\hline Age Group & Frequency & Percentage \\
\hline 0.6 to 10 Years & 32 & 53.3 \\
11 to 20 Years & 9 & 15.0 \\
21 to 30 Years & 4 & 6.7 \\
31 to 40 Years & 5 & 8.3 \\
41 to 50 Years & 6 & 10.0 \\
51 to 60 Years & 3 & 5.0 \\
61 to 70 Years & 1 & 1.7 \\
Total & $\mathbf{6 0}$ & $\mathbf{1 0 0 . 0}$ \\
\hline Mean age \pm SD (Range) & $17.76 \pm 19.15(0.6$ to 70$)$ \\
\hline
\end{tabular}

Out of the sixty patients male was 35(58.3\%) cases and female was $25(41.7 \%)$ cases. The ratio of male and female was 1.4:1(Table 2).

Table 2: Distribution of the Patients according to Sex

\begin{tabular}{lcc}
\hline Gender & Frequency & Percentage \\
\hline Male & 35 & 58.3 \\
Female & 25 & 41.7 \\
Total & $\mathbf{6 0}$ & $\mathbf{1 0 0 . 0}$ \\
\hline
\end{tabular}

The aetiology of patients for obstructive hydrocephalus was recorded. Number of patients having acquedctal stenosis were $31(51.7 \%)$ followed by posterior fossa midline tumour, CPA tumour and pineal region tumour were $14(23.3 \%)$ cases, $9(15.0 \%)$ cases and 6(10.0\%) cases respectively (Table 3 ).

Table 3: Distribution of the Patients according to the Etiology of Hydrocephalus $(n=60)$

\begin{tabular}{lcc}
\hline Etiology of Hydrocephalus & Frequency & Percentage \\
\hline Acqueductal stenosis & 31 & 51.7 \\
Pineal region tumour & 6 & 10.0 \\
CPA tumour & 9 & 15.0 \\
Posterior fossa midline tumour & 14 & 23.3 \\
Total & $\mathbf{6 0}$ & $\mathbf{1 0 0 . 0}$ \\
\hline
\end{tabular}

\section{Discussion}

Hydrocephalus can occur at any age, but it is most common in infants and young children or in adults over the age of 60 . The present study consists of 60 patients. Age range was 6 months to 70 years. According to the National Institute of Neurological Disorders and Stroke, hydrocephalus affects approximately one in every 500 children. The study of Koch and Wegmer ${ }^{4}$ shows that obstructive hydrocephalous occur more frequently in the first decade of life which is consistent with the present 
study result. There is a clear impact of age on obstructive hydrocephalous occurrence rate. In this study, out of 60 patients $35(58.36 \%)$ were male and $25(41.7 \%)$ were female. In a study it has reported that out of 19 patients' male predominance found ${ }^{6}$.

The causes of hydrocephalus are still not well understood. Hydrocephalus may result from inherited genetic abnormalities such as the genetic defect that causes aqueductal stenosis or developmental disorders such as those associated with neural tube defects including spina bifida and encephalocele ${ }^{7}$. Other possible causes include complications of premature birth such as intraventricular hemorrhage, diseases such as meningitis, tumors, traumatic head injury, or subarachnoid hemorrhage, which block the exit of CSF from the ventricles to the cisterns or eliminate the passageway for CSF within the cisterns ${ }^{8}$.

Obstructive hydrocephalus can be a congenital condition and this is in similar findings of the present study where acquiductal stenosis is the most common cause of obstructive hydrocephalous. In these cases, it typically results from a genetic disorder such as spina bifida or as a complication of premature birth with brain hemorrhage. In other cases, the hydrocephalus is an acquired condition that develops later in life due to a brain tumor or cyst, head injury, or an infection such as meningitis. In another study Gangemis et $\mathrm{al}^{9}$ presented 140 patients with obstructive hydrocephalus and have reported that the common etiology of hydrocephalus was acquiductal stenosis in 95 cases and compression by tumour in 45 cases. In present study, the etiology of hydrocephalus is acquiductal stenosis in 31 cases and compression by tumour in 29 cases which is consistent with the previous study.

\section{Conclusion}

In conclusion obstructive hydrocephalous is most commonly found in younger age group. In the majority of cases acquedctal stenosis is the most frequently detected etiology of obstructive hydrocephalous. Posterior fossa midline tumour is the 2nd most common cause of obstructive hydrocephalous.

\section{References}

1. Kaye AH. Raised intracranial pressure and hydrocephalus, Kaye A (ed.) Essential Neurosurgery, 3rd edition, Blackwell Publishing Ltd, Massachusetts, USA, 2005:31-36

2. Goel AK, Pandya SK. Hydrochephalus, in Text Book of Neurosurgery, eds. Ramamurthi and Tandon PN, 2nd edition, B.I. Churchill Livingstone Pvt. Ltd. New Delhi, 1996:195-216

3. Singh D, Gupta V, Goel A, Singh H, Sinha S, Singh A, et al. Endoscopic third ventriculostomy in obstructed hydrocephalus. Neurology India 2003;51(1):39-42

4. Koach WD, Wagmer W. Success and failure of endoscopic third ventriculostomy in young infants: are there different age distributions? Childs Nerv Syst 2006;22(12):1537- 1541

5. Sandrine DE, Ribaupierre B, Rilliet D, Vernet O. Third ventritruculostomy vs ventriculoperitoneal shunt in pediatric obstructive hydrocephalus:results from a Swiss series and literature review', Child Nerv Syst 2007;23:527-533

6. Teo C, Mobbs R. Neuroendoscopy. In: SS Rengachary and RG Ellenbogen (eds.), Principles of Neurosurgery, 2nd edition, Elsevier Mosby, London, 2005;146-147

7. Fukuhara T, Vorster SJ, Luciano MG. Risk factors for failure of endoscopic third ventriculostomy for obstructive hydrocephalus. Neurosurgery. 2000;46(5):1100-11

8. Beni-Adani L, Biani N, Ben-Sirah L, Constantini S. The occurrence of obstructive vs absorptive hydrocephalus in newborns and infants: relevance to treatment choices. Child's Nervous System. 2006;22(12):1543-63

9. Gangemi M, Mascari C, Maiuri F, Godano U. Long-Term outcome of Endoscopic Third Ventriculostomy in Obstructive Hydrocephalus. Minim invas Neurosurg 2007;50:265-269 